\title{
Photocatalytic antibacterial application of zinc oxide nanoparticles and self-assembled networks under dual UV irradiation for enhanced disinfection
}

This article was published in the following Dove Medical Press journal: International Journal of Nanomedicine

\author{
Su-Eon Jin' \\ Jun Eon Jin² \\ Woochul Hwang ${ }^{3}$ \\ Seok Won Hong ${ }^{4}$
}

'Research Institute for Medical Sciences, College of Medicine, Inha University, Incheon 222 12, Korea; ${ }^{2}$ College of Electrical Engineering, Korea University, Seoul 0284I, Korea; ${ }^{3}$ ECOSET Co., Ltd., Ansan I56/0, Korea; ${ }^{4}$ Korea Institute of Science and Technology, Seoul 02792, Korea
Correspondence: Su-Eon Jin Research Institute for Medical Sciences, College of Medicine, Inha University, 100 Inha-ro, Michuhol-gu, Incheon 22212, Korea

Email jins@inha.ac.kr
Background: Zinc oxide ( $\mathrm{ZnO}$ ) nanoparticles and their networks have been developed for use in various applications such as gas sensors and semiconductors.

Aim: In this study, their antibacterial activity against Escherichia coli under dual ultraviolet (UV) irradiation for disinfection was investigated.

Materials and methods: $\mathrm{ZnO}$ nanoparticles were synthesized and immobilized onto silicon (Si) wafers by self-assembly. The physicochemical properties and antibacterial activity of $\mathrm{ZnO}$ nanoparticles and their networks were evaluated. Gene ontology was analyzed and toxicity levels were also monitored.

Results: Synthesized $\mathrm{ZnO}$ nanoparticles were spherical nanocrystals ( $<100 \mathrm{~nm}$; Zn, 47\%; $\mathrm{O}, 53 \%$ ) that formed macro-mesoporous three-dimensional nanostructures on Si wafers in a concentration-dependent manner. $\mathrm{ZnO}$ nanoparticles and their networks on $\mathrm{Si}$ wafers had an excellent antibacterial activity against $E$. coli under dual UV irradiation ( $>3 \log \mathrm{CFU} / \mathrm{mL})$. Specifically, arrayed $\mathrm{ZnO}$ nanoparticle networks showed superior activity compared with free synthesized $\mathrm{ZnO}$ nanoparticles. Oxidative stress-responsive proteins in E. coli were identified and categorized, which indicated antibacterial activity. Synthesized $\mathrm{ZnO}$ nanoparticles were less cytotoxic in $\mathrm{HaCaT}$ with an IC50 of $6.632 \mathrm{mg} / \mathrm{mL}$, but phototoxic in Balb/c 3T3.

Conclusion: The results suggested that $\mathrm{ZnO}$ nanoparticles and their networks can be promising photocatalytic antibiotics for use in next-generation disinfection systems. Their application could also be extended to industrial and clinical use as effective and safe photocatalytic antibiotics.

Keywords: zinc oxide nanoparticles, immobilization, dual UV, antibacterial, disinfection, toxicity

\section{Introduction}

Zinc oxide $(\mathrm{ZnO})$ nanoparticles have shown promise as an alternative to titanium oxide $\left(\mathrm{TiO}_{2}\right)$ nanoparticles in energy conservation and transfer applications such as batteries, solar cells, transistors, photocatalysis, purification, and biosensing. ${ }^{1,2}$ Recently, metal oxide nanoparticles have been extensively studied as nanoantibiotics for enhanced disinfection, particularly for drug-resistant bacteria and parasites. ${ }^{3,4}$ Under ultraviolet (UV) irradiation, these particles mediate oxidative stress in microorganisms. ${ }^{5,6}$ Although $\mathrm{ZnO}$ is a $\mathrm{Zn}$-based compound generally recognized as safe by the US Food and Drug Administration, ${ }^{7,8}$ the safety of $\mathrm{ZnO}$ nanoparticles should be confirmed. Exposure risks to the environment and human health also need to be investigated and minimized.

$\mathrm{ZnO}$ nanoparticles are attractive potential broad-spectrum nanoantibiotics. $\mathrm{ZnO}$ nanoparticles and their nanoparticles adopted by other metal/metal oxides and other polymers have antimicrobial activity against Escherichia coli, ${ }^{6,8-11}$ Staphylococcus aureus, ${ }^{8-10}$ Klebsiella pneumoniae, ${ }^{11} \mathrm{M} 13$ bacteriophages, ${ }^{6}$ and skin-specific 
pathogens ${ }^{12}$ with/without UV irradiation. They also have antimicrobial activity against methicillin-resistant $S$. aureus based on modification of reactive oxygen species (ROS)-mediated pyridine synthesis and multiple metabolic pathways. ${ }^{13}$ Therefore, engineered $\mathrm{ZnO}$ nanoparticles and their networks could be used to develop effective and safe antimicrobial agents.

Immobilization of nanoparticles on a solid plate has the advantage of eliminating the risk of nanoparticle exposure in unintended targets. ${ }^{14-17}$ Specifically, nanofabrication by self-assembly is a valuable technique for developing three-dimensional nanostructures with smart properties for enhanced efficacy and safety. ${ }^{18,19}$ Nanowires, nanocages, nanofilms, and nanosheets have been developed into revolutionary nanostructures. ${ }^{20,21} \mathrm{ZnO}$ nanoparticle aggregates and multilevel porous $\mathrm{ZnO}$ nanoparticle networks immobilized on solid plates can be effectively and safely applied for disinfection purposes based on their enhanced energy exchange and transfer.

In the present study, we hypothesized that $\mathrm{ZnO}$ nanoparticles and their three-dimensional networks attached to silicon ( $\mathrm{Si}$ ) wafers via self-assembly could have enhanced antibacterial activity against $E$. coli under dual UV irradiation (UV-A and UV-C). ZnO nanoparticles were thus synthesized and immobilized on Si wafers, and physicochemical characterization and antibacterial activity tests were performed. Cytotoxicity in $\mathrm{HaCaT}$ and ARPE-19 cells and phototoxicity in Balb/c 3T3 cells were also investigated. Nano-to-micro$\mathrm{ZnO}$ (hybrid- $\mathrm{ZnO}$ ) and nano- $\mathrm{ZnO}$ particles were used as conventional $\mathrm{ZnO}$ particle products.

\section{Materials and methods Chemicals}

Hybrid- and nano-ZnO particles were purchased from Sigma (St Louis, MO, USA). Ethanol, hexane, zinc acetylacetonate hydrate, and oleylamine were also obtained from Sigma. All chemicals were of reagent grade without further purification. Deionized water was obtained using a Milli-Q water purification system (Millipore, Billerica, MA, USA).

\section{Synthesis of $\mathrm{ZnO}$ nanoparticles}

$\mathrm{ZnO}$ nanoparticles were synthesized from zinc acetylacetonate hydrate $(0.2 \mathrm{~g})$ and oleylamine $(70 \%, 5 \mathrm{~g})$. This mixture was heated at $80^{\circ} \mathrm{C}$ for 30 minutes under an argon atmosphere and then kept at $150^{\circ} \mathrm{C}$ for 1 hour. After cooling to room temperature, it was poured into $200 \mathrm{~mL}$ of ethanol to produce white precipitate. The precipitate was filtered, washed three times with ethanol, and dried. The removal of residual amines was confirmed by Fourier transform-infrared spectroscopy.

\section{Nanofabrication by self-assembly}

$\mathrm{ZnO}$ nanoparticles were arrayed on Si wafers (Semiroad, Inc., Paju, Kyunggi-do, Korea) to develop three-dimensional nanostructure networks. Si wafers were rinsed and residual solvents were removed. Nanoparticle dispersions in hexane were dropped onto the $\mathrm{Si}$ wafers as $0.05-1.0 \mathrm{mg}$ of $\mathrm{ZnO}$ nanoparticles per unit Si wafer $\left(0.5 \times 0.5 \mathrm{~cm}^{2}\right)$. Then, the wafers were incubated at room temperature in the dark.

\section{X-ray photoelectron spectroscopy (XPS)}

Atomic composition was determined using XPS (K-Alpha, Thermo Fisher Scientific Inc., Waltham, MA, USA) with a source of monochromated Al K-alpha.

\section{Field emission-scanning electron microscopy (FE-SEM) with energy- dispersive X-ray spectroscopy (EDS)}

The morphology was monitored using FE-SEM (S-4300SE, Hitachi, Co. Ltd., Tokyo, Japan) operated at an acceleration voltage of $15.0 \mathrm{kV}$. Samples were investigated after platinum coating. Particle size distribution was analyzed using ImageJ (NIH). EDS analysis was also performed after particle surface scanning (20 runs) at 1,800× magnification. Samples used for EDS analyses were examined before platinum coating.

\section{Field emission-transmission electron microscopy (FE-TEM)}

The crystal shape and size were observed using FE-TEM (JEM-2100F, Jeol, Co. Ltd., Peabody, MA, USA) at an acceleration voltage of $100 \mathrm{kV}$. Nanoparticles were dispersed in hexane and dropped onto a copper grid (300 meshes). They were then investigated after drying in the dark. FETEM images were analyzed using Gatan Microscopy Suite Software (Gatan, Inc., Pleasanton, CA, USA).

\section{Atomic force microscopy (AFM)}

The surface topology and phase were determined using AFM (Nanoscope Multimode IVa, Bruker, Billerica, MA, USA) in tapping mode. Images were analyzed using NanoScope software (5.31r1, Veeco Instruments, Inc., Plainview, NY, USA).

\section{Collimated beam device (CBD)}

A CBD was prepared using a dual UV lamp ( $85 \mathrm{~cm}$ in length) with both UV-A (315-400 nm) and UV-C (100-280 nm; ECOSET Co., Ltd., Ansan, Korea) connected to an electronic controller of $40 \mathrm{~W} / \mathrm{m}^{2}$, which can be adjusted to emit focused and narrow light. ${ }^{6}$ The dual UV lamp was coated on half of the surface by length. The uncoated side of the UV lamp was used. UV intensity was measured at the Petri dish using a 
spectrometer (Jaz System; Ocean Optics, Inc., Petaluma, CA, USA) with Spectra Suite software (Ocean Optics, Inc.). The UV dose $\left(\mathrm{J} / \mathrm{m}^{2}\right)$ was calculated by multiplying the UV lamp intensity $\left(\mathrm{W} / \mathrm{m}^{2}\right)$ by exposure time $(\mathrm{s})$.

\section{Antibacterial activity test against $E$. coli}

E. coli (American Type Culture Collection, ATCC, Manassas, VA, USA) was used as a model microorganism. For particle effects, $\mathrm{ZnO}$ nanoparticles were dispersed in water at 0.05-1.0 mg/mL. They were irradiated once for 30 seconds while incubated with $E$. coli $\left(2.0 \times 10^{4} \mathrm{CFU}\right)$ for 5 minutes. Tests were performed in triplicate. Then, samples were collected, diluted, and added to each Petrifilm ${ }^{\mathrm{TM}}$ (3M, Maplewood, MN, USA). The films were incubated in the dark at $35^{\circ} \mathrm{C}$ overnight and colonies were counted using Image $(\mathrm{NIH})$ after obtaining images. Water samples were also collected from three facilities with sterile 1-L-sized bottles to monitor the antibacterial activity of dual UV-ZnO nanoparticle treatments against E. coli. These were stored at $4^{\circ} \mathrm{C}$ for 7 days, and antibacterial activity testing was performed. For the immobilized particle network on Si wafers $(0,0.05,0.1,0.5$, and $1.0 \mathrm{mg} /$ wafer $)$, one piece of Si wafer was used for each Petri dish. E. coli $\left(2.0 \times 10^{4}\right.$ CFU) in water was poured into each Petri dish after fixing the Si wafer to the bottom. After dual UV irradiation (5 and 10 seconds), they were incubated in the dark (5 minutes and 2 hours). Then, each sample was handled as mentioned above.

\section{Systems biology analysis}

Gene ontology (GO) terms related to oxidative stress from metal oxides were analyzed for E. coli using EcoCyc (SRI International, Menlo Park, CA, USA). ${ }^{22}$ Search results from the $E$. coli database (EcoCyc) were summarized based on the hierarchy of biological process groups. Members of GO terms were also listed.

\section{Cytotoxicity testing}

$\mathrm{HaCaT}$ (human keratinocyte, CLS Cell Lines Service GmbH, Eppelheim, Germany) and ARPE-19 (human retinal pigmented epithelial cell, ATCC) were cultured in DMEM and DMEM/ F12 supplemented with 10\% FBS (Thermo Fisher Scientific, Waltham, MA, USA) and $100 \mathrm{U}$ of penicillin-streptomycin (Thermo Fisher Scientific), respectively. They were incubated at $37^{\circ} \mathrm{C}$ in a $\mathrm{CO}_{2}$ incubator with $5 \% \mathrm{CO}_{2}$ and appropriate humidity. HaCaT and ARPE-19 cells were seeded at $1.0 \times 10^{4}$ cells/ well in 96-well plates. After 48-hour incubation, cells were treated with free nanoparticles in water at $0.01-10 \mathrm{mg} / \mathrm{mL}$. After 48 and 72 hours of incubation, CellVia ${ }^{\circledR}$ (Young In Frontier Co. Ltd., Seoul, Korea) was diluted with each medium and applied to cells. After 4-hour incubation in $\mathrm{C} \mathrm{O}_{2}$ incubator, absorbance was measured at $450 \mathrm{~nm}$. The reference wavelength was $600 \mathrm{~nm}$. Cell viability at concentration $C$ was calculated by

Cell viability (\%)

$=\frac{\left(\text { Absorbance }_{450 \mathrm{~nm}}-\text { Absorbance }_{600 \mathrm{~nm}}\right) \text { at } C \mathrm{mg} / \mathrm{mL}}{\left(\text { Absorbance }_{450 \mathrm{~nm}}-\text { Absorbance }_{600 \mathrm{~nm}}\right) \text { at } 0 \mathrm{mg} / \mathrm{mL}} \times 100$

EC50 was also calculated using Excel software (2010 version, Microsoft, Redmond, WA, USA).

\section{Phototoxicity testing}

Balb/c 3T3 (mouse embryonic fibroblast, A31, ATCC) cells were cultured in DMEM (Thermo Fisher Scientific) with 10\% newborn calf serum (Thermo Fisher Scientific) and $100 \mathrm{U}$ of penicillin-streptomycin (Thermo Fisher Scientific), which were incubated at $37^{\circ} \mathrm{C}$ with $5 \% \mathrm{CO}_{2}$ and appropriate humidity. For tests, they were seeded at $1.0 \times 10^{3}$ cells/well in 96 -well plates. After 48-hour incubation, cells were rinsed and incubated with Earle's balanced salt solution (EBSS, Thermo Fisher Scientific) for 1 hour. Then, they were treated with nanoparticles in EBSS (Thermo Fisher Scientific) at 0.001-1.0 mg/mL. One group was incubated under dual UV at room temperature for 30 minutes and the other group was incubated in the dark at room temperature for 30 minutes. After replacing the culture medium, cells were incubated overnight and the neutral red uptake testing was performed. Photo-irritation-factor (PIF) and mean photo effect (MPE) were calculated using Phototox software (ver 2.0, Bundesinstitut für Risikobewertung, Berlin, Germany). Substances were classified by PIF and MPE values: probably phototoxic $(2<\mathrm{PIF}<5 ; 0.1<\mathrm{MPE}<0.15)$ and phototoxic $(5<$ PIF; $0.15<$ MPE). Chlorpromazine was used as the control.

\section{Statistical analysis}

The results are expressed as the mean $\pm \mathrm{SD}$. The statistical significance of the differences between groups was tested using the Student's $t$-test, with $p<0.05$ considered significant.

\section{Results}

\section{Morphology, crystallinity, particle size distribution, and atomic composition}

Synthesized $\mathrm{ZnO}$ nanoparticles generated spherical cluster shapes up to $3 \mu \mathrm{m}$ (Figure 1A). Single $\mathrm{ZnO}$ nanoparticle was formed by uneven surface, which showed crystallinity with d-spacing of $0.265 \mathrm{~nm}$ for nanocrystal (002) (JCPDS 36-1451; Figure 1B). The average size was $48.3 \pm 3.5 \mathrm{~nm}$ in diameter with a narrow size distribution (Figure 1C). The aggregates generated a macro-mesoporous network based on interparticle interactions (Figure 1D). However, hybrid-ZnO particles were a 


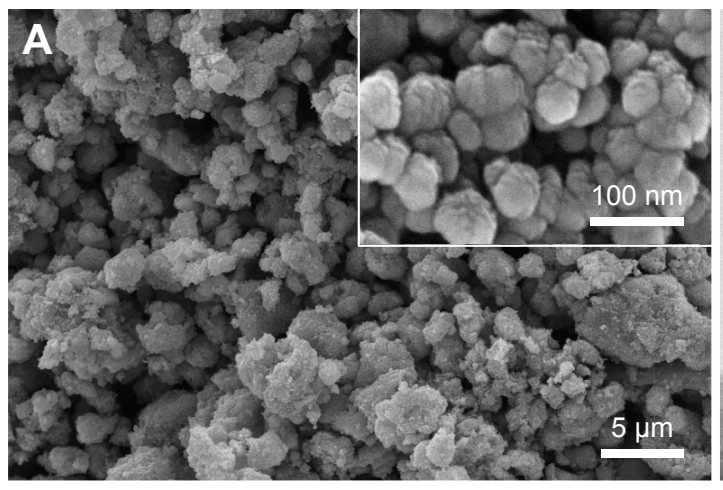

C

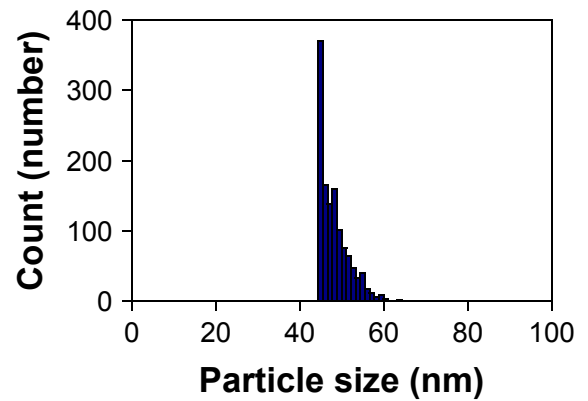

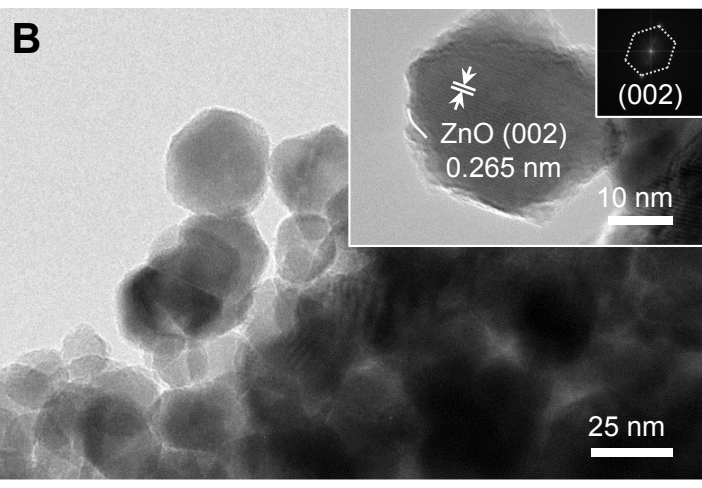

D

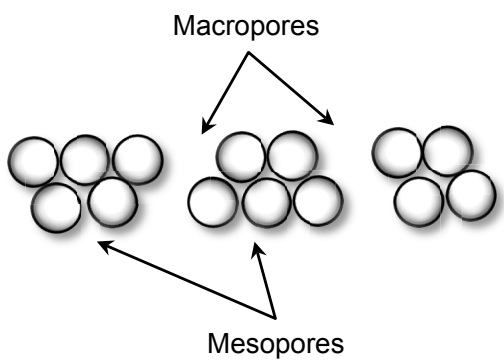

Figure I Synthesized ZnO nanoparticles: (A) FE-SEM images, (B) FE-TEM images with crystallinity and electron diffraction, (C) size distribution plot, and (D) schematic diagram of macro-mesopores.

Abbreviations: FE-SEM, field emission-scanning electron microscopy; FE-TEM, field emission-transmission electron microscopy; ZnO, zinc oxide.

mixture of needle, rod, and sphere-shaped particles of nanoscale to microscale size (Figure S1A and $\left.\underline{\mathrm{A}}^{\prime}\right)$ and nano-ZnO particles had small rectangular bullet shapes (Figure $\mathrm{S} 1 \mathrm{~B}$ and $\left.\underline{\mathrm{B}}^{\prime}\right)$. For atomic composition analysis, synthesized $\mathrm{ZnO}$ nanoparticles consisted of $47.38 \% \mathrm{Zn}$ and $52.62 \% \mathrm{O}$ (Table 1). Compared with synthesized $\mathrm{ZnO}$ nanoparticles, hybrid- and nano- $\mathrm{ZnO}$ particles had $44.8 \%$ and $48.16 \% \mathrm{Zn}$ and $55.2 \%$ and $51.84 \%$ $\mathrm{O}$, respectively. On XPS spectra, binding energy peaks of $\mathrm{Zn} 2 \mathrm{p}$ were detected at $1,021 \mathrm{eV}$, and 1,044 eV for $\mathrm{Zn} 2 \mathrm{p}_{3 / 2}$ and $\mathrm{Zn} 2 \mathrm{p}_{1 / 2}$ (Figure S2). An O1s peak was also detected at $530 \mathrm{eV}$.

\section{Nanostructure network generation of immobilized $\mathrm{ZnO}$ nanoparticles on $\mathrm{Si}$ wafers}

Synthesized $\mathrm{ZnO}$ nanoparticles on $\mathrm{Si}$ wafers were in a highly ordered network with macro-mesopores (Figure 2) compared with hybrid- and nano- $\mathrm{ZnO}$ particles on the

Table I Composition of $\mathrm{ZnO}$ particles

\begin{tabular}{l|l|l|l}
\hline \multirow{2}{*}{$\begin{array}{l}\text { Binding energy } \\
\text { peak }\end{array}$} & \multicolumn{4}{|l}{ Atomic composition (\%) } \\
\cline { 2 - 4 } & Hybrid-ZnO & Nano-ZnO & $\begin{array}{l}\text { Synthesized } \\
\text { ZnO }\end{array}$ \\
\hline Zn2p & 44.8 & 48.16 & 47.38 \\
Ols & 55.2 & 51.84 & 52.62 \\
\hline
\end{tabular}

Abbreviation: $\mathrm{ZnO}$, zinc oxide.
$0.5 \mathrm{mg} / \mathrm{Si}$ wafer (Figure S3). After simple dripping of a $\mathrm{ZnO}$ nanoparticle hexane suspension onto Si wafers, the patterned macropores of hemispherical and spherical $\mathrm{ZnO}$ nanoparticle aggregates were generated by gradual solvent evaporation, while mesopores in network were maintained (Figure 2A). As drop concentrations increased (0.05-1.0 mg/Si wafer), layer-by-layer structures in the $\mathrm{ZnO}$ nanoparticle network were produced after hexane evaporation (Figure 2B-Q). The atomic compositions of the aggregates on Si wafers were confirmed with EDS spectra (Figure 2E, I, M, and Q).

\section{Arrayed $\mathrm{ZnO}$ nanoparticle interactions on Si wafers}

Figure 3 shows the AFM topology and phase of immobilized $\mathrm{ZnO}$ nanoparticles on the $\mathrm{Si}$ wafers. Since $\mathrm{ZnO}$ nanoparticles at $0.05 \mathrm{mg} / \mathrm{Si}$ wafer were used, small $\mathrm{ZnO}$ nanoparticle aggregates were generated $(0.2-0.3$ to $2.3-2.6 \mu \mathrm{m}$ in diameter) that did not form a hierarchically porous network. During aggregate formation (Figure 3A, white arrow), small $\mathrm{ZnO}$ nanoparticle clusters formed with mesopores and grew into large aggregates ( $>2 \mu \mathrm{m}$ in diameter) with $353.06 \mathrm{~nm}$ roughness (Figure 3B). Small $\mathrm{ZnO}$ nanoparticle clusters $(<1.0 \mu \mathrm{m}$ in diameter) remained on the Si wafers (Figure 3C). From the phase results, hexagonal forms of $\mathrm{ZnO}$ nanoparticle aggregates were included in both the small and large 
A

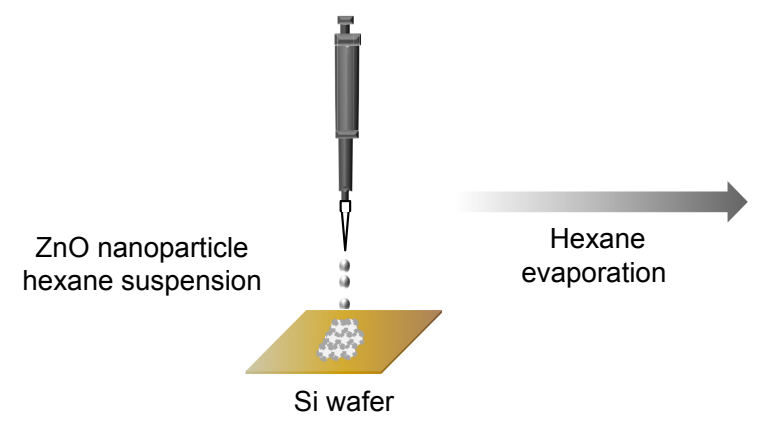

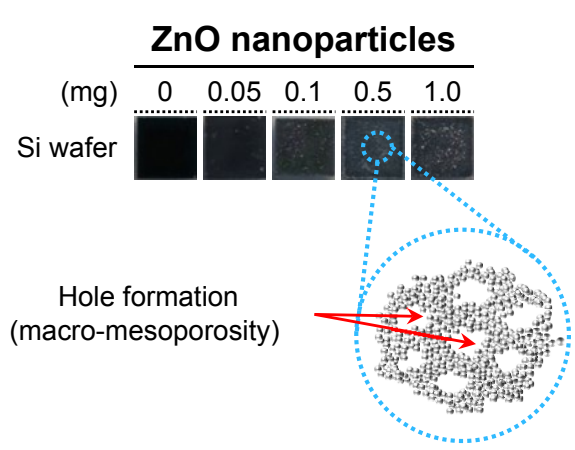
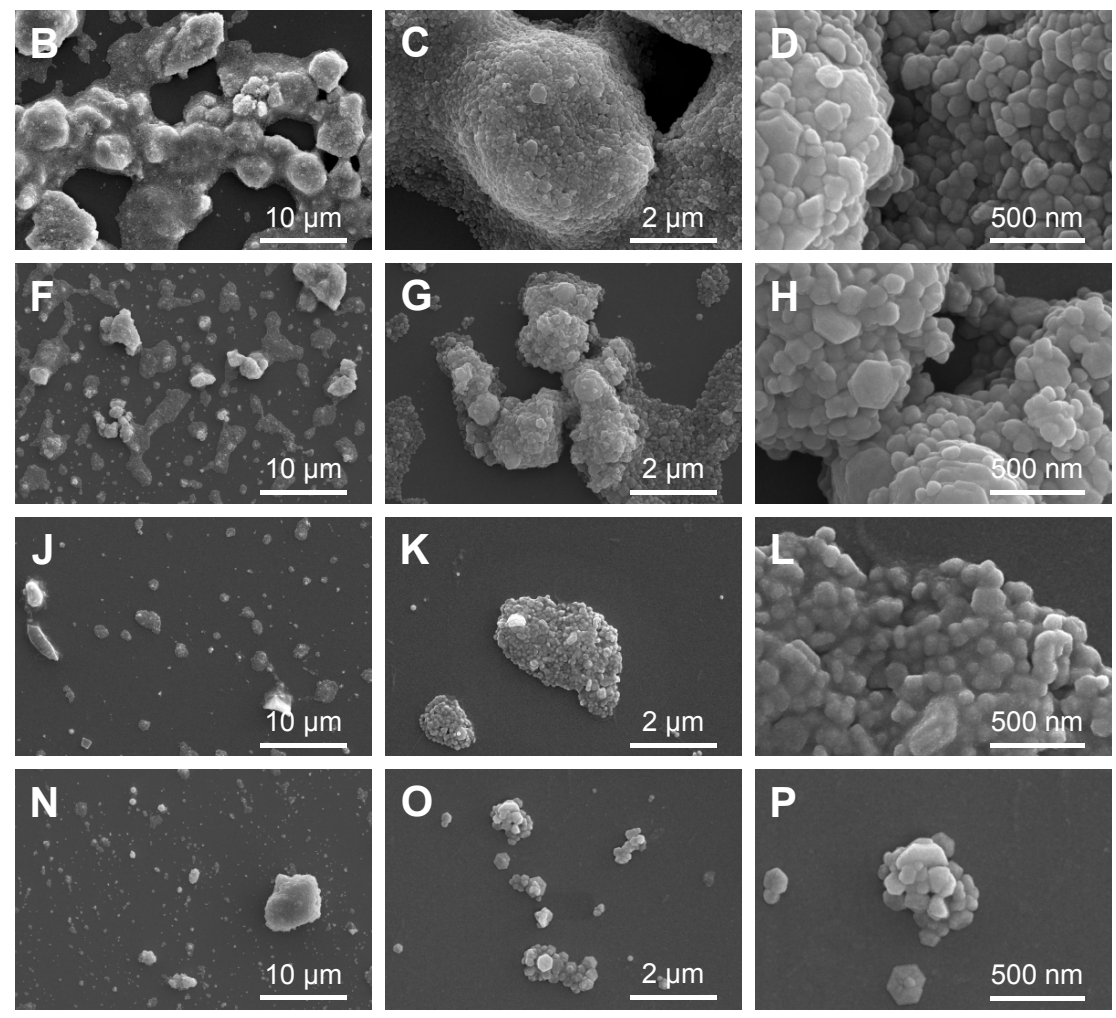
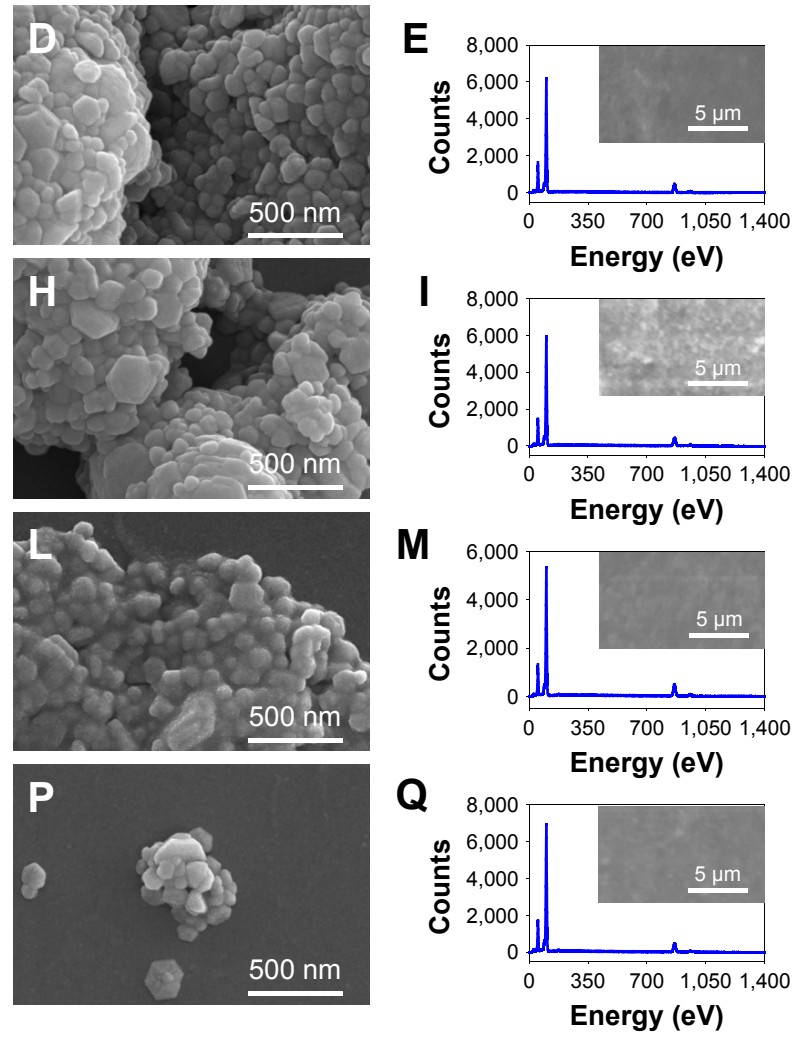

Figure 2 Arrayed $\mathrm{ZnO}$ nanoparticles on Si wafers.

Notes: (A) In situ array on an Si wafer and (B-P) FE-SEM images with EDS spectra. Synthesized ZnO nanoparticles were loaded at (B-E) I.0, (F-I) 0.5, (J-M) 0.I, and (N-Q) $0.05 \mathrm{mg}$ per unit Si wafer $\left(0.5 \times 0.5 \mathrm{~cm}^{2}\right)$. O at $53 \mathrm{eV} ; \mathrm{Zn}$ at $103 \mathrm{eV}, 864 \mathrm{eV}$, and $957 \mathrm{eV}$ in EDS spectra. (E, I, M, and $\left.\mathbf{Q}\right)$ Scanned images of ZnO nanoparticles on Si wafers were added onto EDS spectra.

Abbreviations: EDS, energy-dispersive X-ray spectroscopy; FE-SEM, field emission-scanning electron microscopy; Si, silicon; ZnO, zinc oxide.

aggregates (Figure 3D), which adopted a wurtzite crystal structure. The AFM results of $\mathrm{ZnO}$ nanoparticle aggregates on Si wafers are comparable to the FE-SEM results.

\section{Dual UV irradiation}

The average intensity level was $54.5 \pm 1.80 \mathrm{~W} / \mathrm{m}^{2}$ of the whole wavelength divided by $10.5 \pm 0.0330 \mathrm{~W} / \mathrm{m}^{2}$ of UV-A and $43.2 \pm 1.80 \mathrm{~W} / \mathrm{m}^{2}$ of UV-C (1:4.13 of UV-A to UV-C) (Figure 4). Half of the dual UV lamp by length was coated to block UV light scattering and to maximize the dual UV intensity to the uncoated side of lamp. A CBD was used to control the dual UV intensity at Petri dishes.

\section{Antibacterial activity of dual UV- irradiated $\mathrm{ZnO}$ nanoparticles against E. coli}

The dual UV-ZnO nanoparticle system had antibacterial activity against $E$. coli (Figure 5A), which was enhanced even at the lowest concentration $(0.05 \mathrm{mg} / \mathrm{mL})$ compared with UV alone. Hybrid-ZnO particles also offered excellent activity at the lowest concentration $(0.05 \mathrm{mg} / \mathrm{mL})$, whereas nano-ZnO particles showed considerable activity at the highest concentration $(1.0 \mathrm{mg} / \mathrm{mL})$. In a 100 -fold dilution of $E$. coli (Figure 5B), $10 \mathrm{CFU} / \mathrm{mL}$ was detected without 

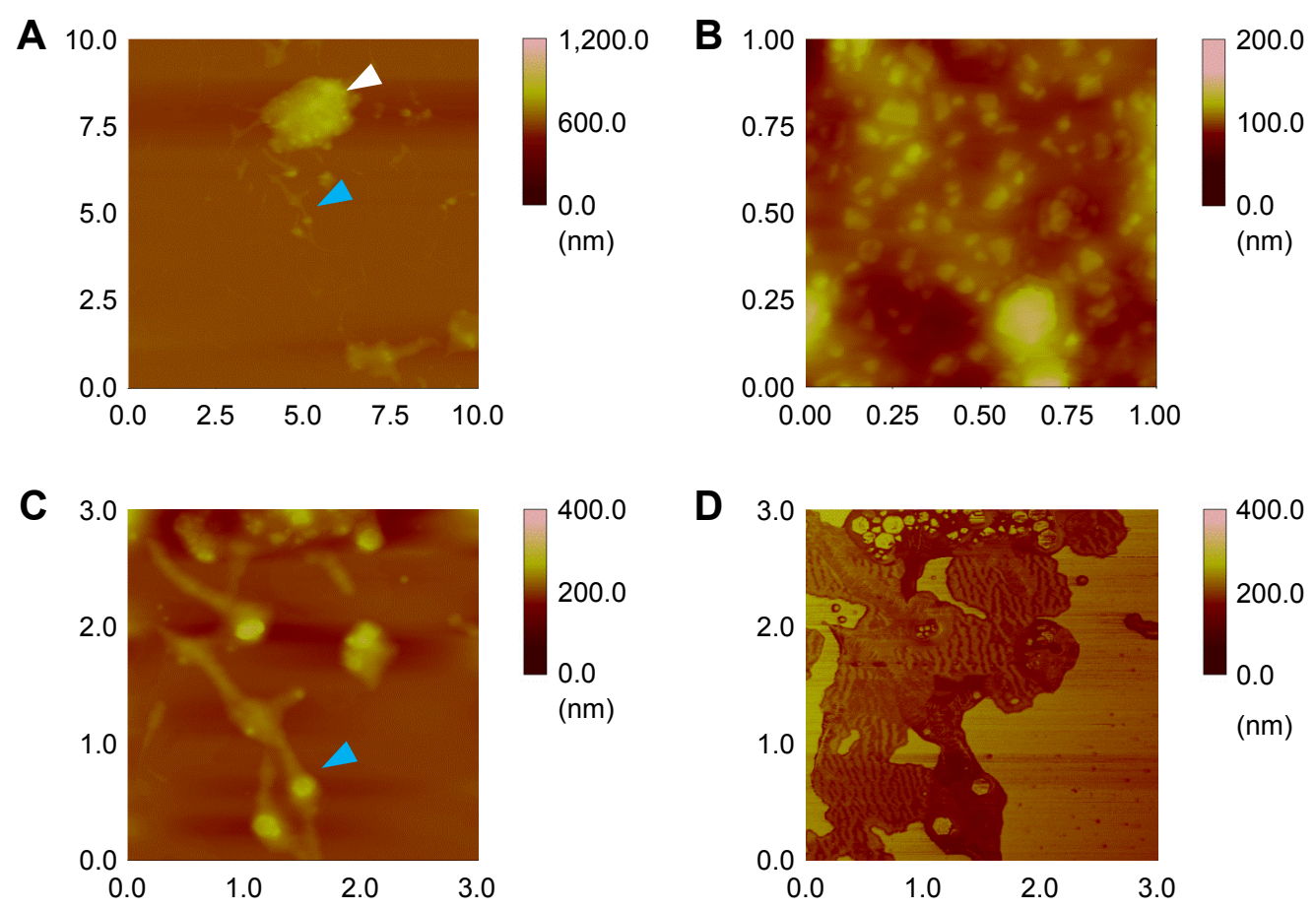

Figure 3 Synthesized $\mathrm{ZnO}$ nanoparticle interactions on Si wafers: (A-C) topology and (D) phase of AFM images at $0.05 \mathrm{mg} /$ wafer. Note: White and blue arrows represent the expanded areas to be confirmed.

Abbreviations: AFM, atomic force microscopy; $\mathrm{ZnO}$, zinc oxide.

UV irradiation. After dual UV irradiation for 30 seconds, no colonies were detected (Figure 5D). Their disinfection E. coli $(7 \mathrm{CFU} / \mathrm{mL}$ ) was still detected (Figure 5C). However, potential was also investigated in samples from L1, L2, and after dual UV-irradiated (30 seconds) $\mathrm{ZnO}$ nanopar- $\mathrm{L} 3$ facilities (Figure 5E-O). Colonies were too numerous to ticle $(0.05 \mathrm{mg} / \mathrm{mL}$, incubation for 5 minutes) treatment, count in the L1 facility (Figure $5 \mathrm{G})$ compared with the others

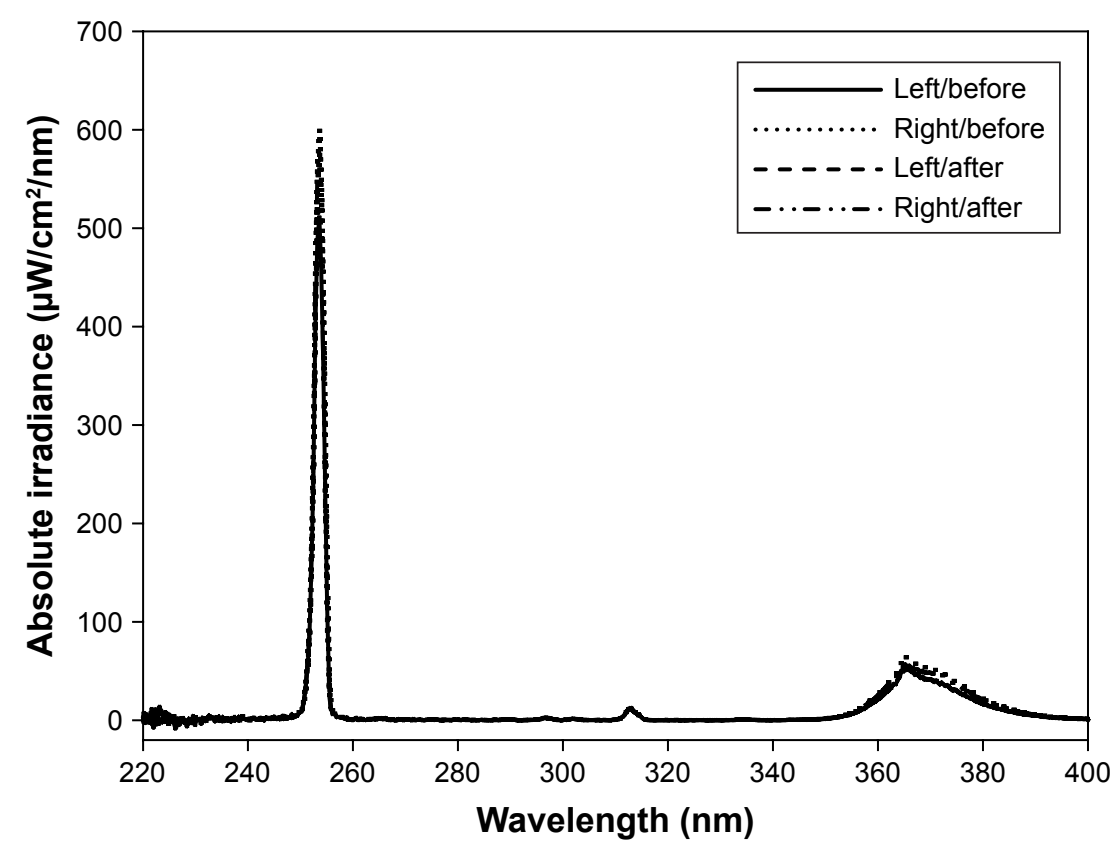

Figure 4 Dual UV spectra.

Notes: UV-A and UV-C intensities were maintained before and after antibacterial activity tests. Left and right represent the outputs for two-pathway UV irradiation in a CBD. Abbreviations: CBD, collimated beam device; UV, ultraviolet. 
A

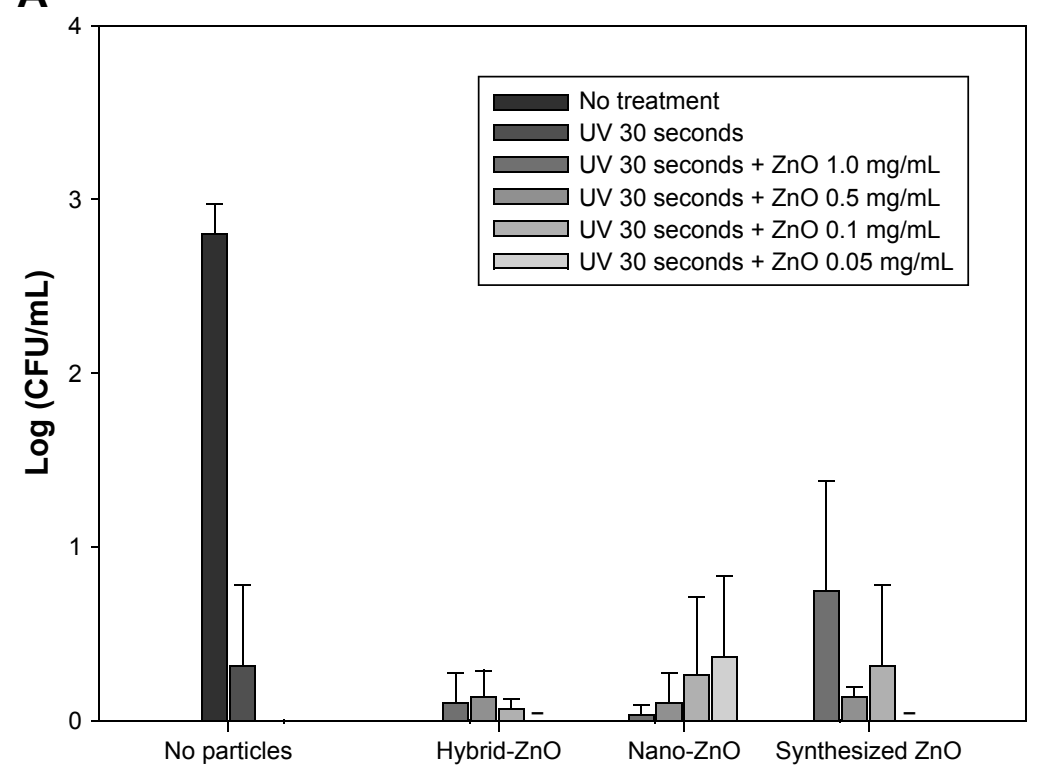

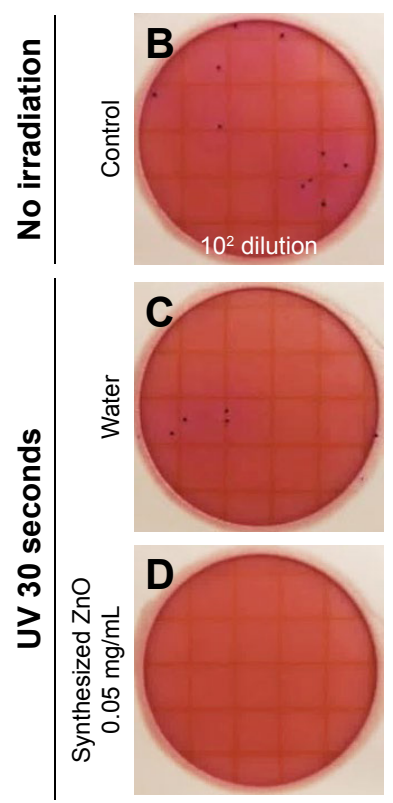

E

$\mathbf{F}$

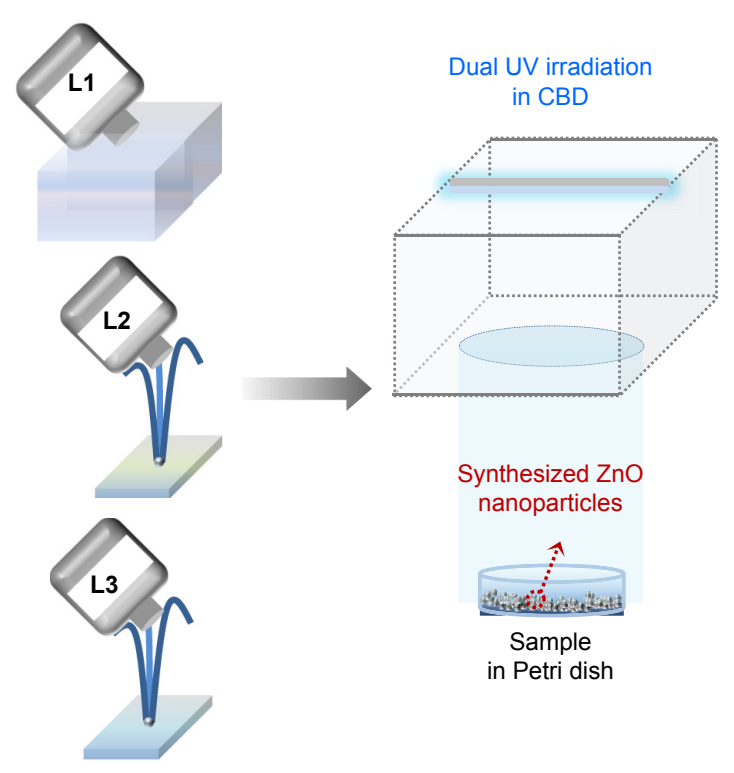

No treatments
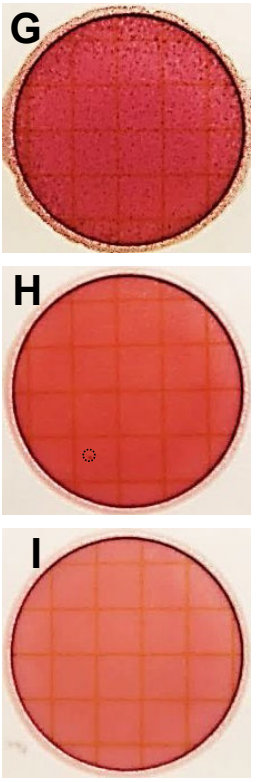

Dual UV alone
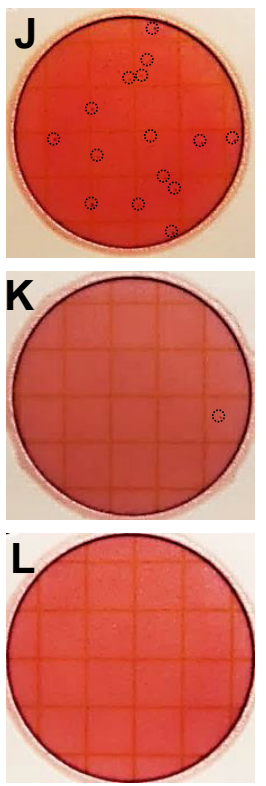

Dual UV-ZnO (0.05 mg/mL)
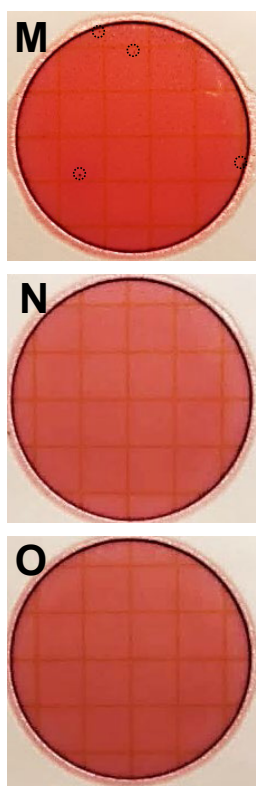

Figure 5 Antibacterial activity of the dual UV-irradiated $\mathrm{ZnO}$ nanoparticles against Escherichia coli.

Notes: (A) Plots of $\mathrm{ZnO}$ particle concentration vs log (CFU/mL). Representative plate images of (B) E. coli colonies (I $0^{2}$ dilution) with no treatment, (C) E. coli colonies after dual UV irradiation alone (30 seconds), and (D) after dual UV-irradiated (30 seconds)-ZnO nanoparticle $(0.05 \mathrm{mg} / \mathrm{mL})$ treatment with a 5 -minute incubation period. (E) Schematic diagram of water sampling from LI, L2, and L3 locations (a pool and two fountains) and (F) dual UV irradiation in a CBD with ZnO nanoparticle treatment. (G-O) Representative film images of samples from LI, L2, and L3 treated with/without dual UV-ZnO nanoparticles (G-I, no treatment; J-L dual UV irradiation for 30 seconds; M-O, dual UV [30 seconds]-ZnO nanoparticles [0.05 mg/mL, 5 minutes]). (A) - represents 'not detected'. (J, M, H, and $\mathbf{K})$ Round dot circles represent E. coli colonies.

Abbreviations: $\mathrm{CBD}$, collimated beam device; UV, ultraviolet; $\mathrm{ZnO}$, zinc oxide.

(Figure 5H and I). The dual UV-irradiated $\mathrm{ZnO}$ nanoparticle system showed superior disinfection potential compared with UV alone (Figure 5J and $\mathrm{M}$, round dot circles for $E$. coli colonies). No colonies were detected in the L3 facility (Figure 5I).

\section{Antibacterial activity of dual UV- irradiated $\mathrm{ZnO}$ nanoparticles} immobilized on Si wafers against $E$. coli

Figure 6 shows the antibacterial activity of $\mathrm{ZnO}$ nanoparticleimmobilized Si wafers against $E$. coli. Using these Si wafers 
of arrayed $\mathrm{ZnO}$ nanoparticles, the UV irradiation time was set at 5 and 10 seconds. The UV exposure time was reduced compared to antibacterial activity test of synthesized $\mathrm{ZnO}$ nanoparticles. The samples were also incubated for 5 and 120 minutes after dual UV irradiation. As the concentration of immobilized $\mathrm{ZnO}$ nanoparticles decreased from 1.0 to
$0.05 \mathrm{mg}$, antibacterial activity increased slightly in E. coli (Figure 6A). The incubation time following dual UV irradiation influenced the antibacterial activity for disinfection (Figure 6B-K). Compared with the 5-minute incubation (Figure 6D and F), colonies decreased significantly after the 120-minute incubation of $\mathrm{ZnO}$ nanoparticle-immobilized Si
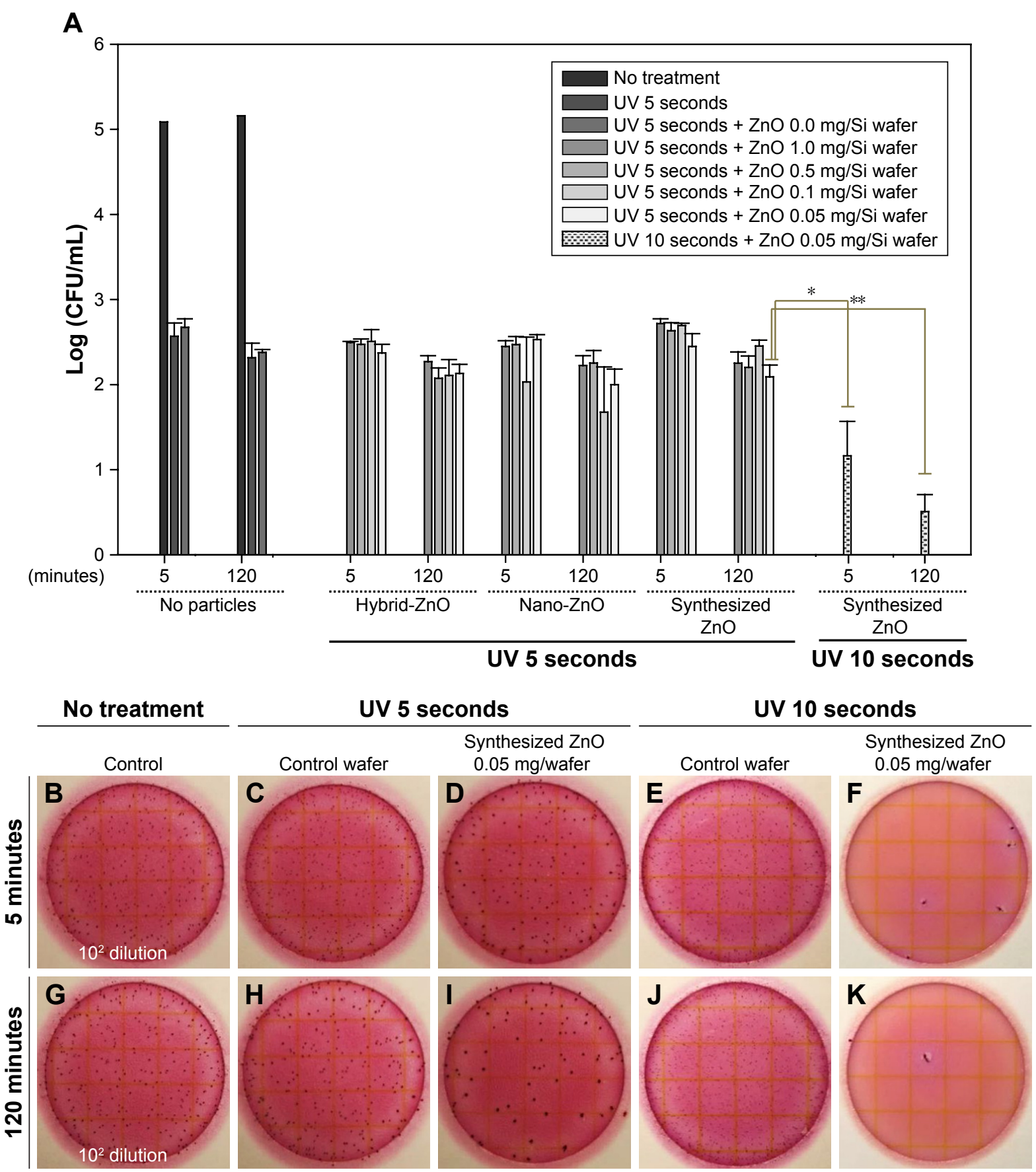

Figure 6 Antibacterial activity of the dual UV-irradiated $\mathrm{ZnO}$ nanoparticle network on Si wafer against Escherichia coli.

Notes: (A) Plots of immobilized $\mathrm{ZnO}$ particle concentration vs $\log (\mathrm{CFU} / \mathrm{mL})$. Representative plate images of (B and $\mathbf{G})$ E. coli colonies (I02 dilution) with no treatment, and E. coli colonies after dual UV irradiation for $(\mathbf{C}$ and $\mathbf{H}) 5$ seconds and $(\mathbf{E}$ and $\mathbf{J}) 10$ seconds and after dual UV-irradiated ZnO nanoparticle network (0.05 mg) treatment - UV irradiation for ( $\mathbf{D}$ and $\mathbf{I}) 5$ seconds and $(\mathbf{F}$ and $\mathbf{K}) \mathbf{I} 0$ seconds; incubation for (B-F) 5 minutes and $(\mathbf{G}-\mathbf{K}) \mid 20$ minutes. $* P<0.05$ and $* * P<0.0$ I.

Abbreviations: $\mathrm{Si}$, silicon; UV, ultraviolet; $\mathrm{ZnO}$, zinc oxide. 
wafers (Figure 6I and K). In the case of dual UV irradiation for 10 seconds, the disinfection potential of immobilized $\mathrm{ZnO}$ nanoparticles on the $0.05 \mathrm{mg} / \mathrm{Si}$ wafer was enhanced $>3$ $\log$ CFU/mL. Zn ion was not detected in water (Table S1).

\section{Interaction of $\mathrm{ZnO}$ nanoparticles with E. coli}

In terms of antibacterial action mechanisms, $\mathrm{ZnO}$ nanoparticles had sorption potential with regard to biomembranes as well as generating ROS, whereas $\mathrm{ZnO}$ nanoparticle networks on solid plates mainly produced ROS and reduced the sorption potential. In other words, cellular responses to ROS generation and multiple scattering in self-assembled and multilevel porous $\mathrm{ZnO}$ nanoparticle networks can be major events for disinfection against $E$. coli (Figure 7). In biological processes, GO terms for oxidative stress in $E$. coli from EcoCyc are summarized in Table S2. Thiol peroxidase, superoxide dismutase, thioredoxin reductase, and lipid hydroperoxide peroxidase were included in objects annotated in GO terms. Specifically, OxyR (oxyR), a bifunctional sensor for oxidative stress, and protein/nucleic acid deglycase 3 (yajL), a chaperone generated in response to oxidative stress to protect proteins, were GO term members. Although metal ion release from metal oxide nanoparticles is a powerful antimicrobial mechanism, no $\mathrm{Zn}$ ion released from $\mathrm{ZnO}$ nanoparticles immobilized on Si wafers $(0.05 \mathrm{mg} / \mathrm{Si}$ wafer $)$ was detected in water after 24-hour incubation.

\section{Cytotoxicity of $\mathrm{ZnO}$ nanoparticles in eye and skin cells}

Cell viability levels of synthesized $\mathrm{ZnO}$ nanoparticles were higher than those of hybrid- and nano-ZnO particles at 0.5-10.0 mg/mL in ARPE-19 and HaCaT cells (Figure 8). Cell viability of ARPE-19 cells (Figure 8A and C) was lower than that of HaCaT cells (Figure $8 \mathrm{~B}$ and D). The IC50 value in HaCaT cells was highest in synthesized $\mathrm{ZnO}$ nanoparticles $(6.632 \mathrm{mg} / \mathrm{mL})$, lower in hybrid-ZnO particles $(4.476 \mathrm{mg} / \mathrm{mL})$, and lowest in nano- $\mathrm{ZnO}$ particles $(1.736 \mathrm{mg} / \mathrm{mL})$ after a 48-hour incubation (Figure 8B). In $\mathrm{HaCaT}$ cells, low-level synthesized $\mathrm{ZnO}$ nanoparticles $(0.01-$ $2.0 \mathrm{mg} / \mathrm{mL} ; 0.01-0.5 \mathrm{mg} / \mathrm{mL}$ ) slightly enhanced cell proliferation levels to $130 \%$ after 48 hours (Figure $8 \mathrm{~B}$ ) and 72 hours (Figure 8D) of incubation. No particle shape effects were detected on $\mathrm{HaCaT}$ cells at concentrations of $0.01-2.0 \mathrm{mg} / \mathrm{mL}$ (Figure S4A-E). These results suggest that synthesized $\mathrm{ZnO}$ nanoparticles had low toxicity in eye and skin cells compared with hybrid- and nano-ZnO particles. In addition, eye cells were more susceptible to $\mathrm{ZnO}$ particles than skin cells.

Dual UV irradiation

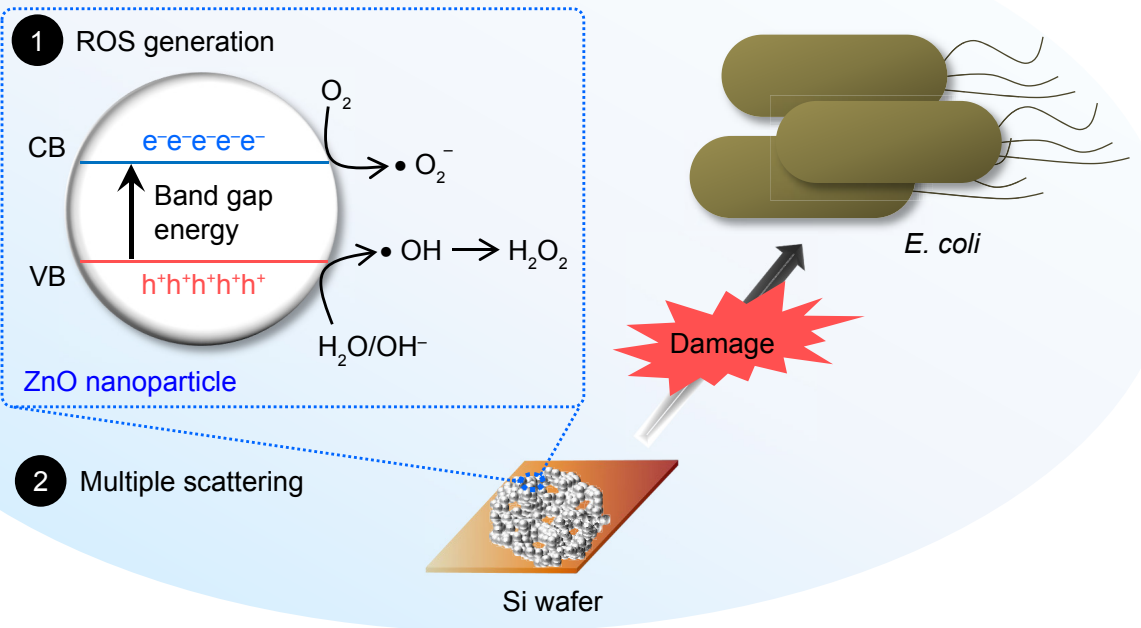

Water

Figure 7 Schematic diagram of the antibacterial mechanisms of synthesized $\mathrm{ZnO}$ nanoparticles and their self-assembled networks against Escherichia coli. Abbreviations: $\mathrm{CB}$, conduction band; ROS, reactive oxygen species; UV, ultraviolet; VB, valence band; ZnO, zinc oxide. 


\section{A}

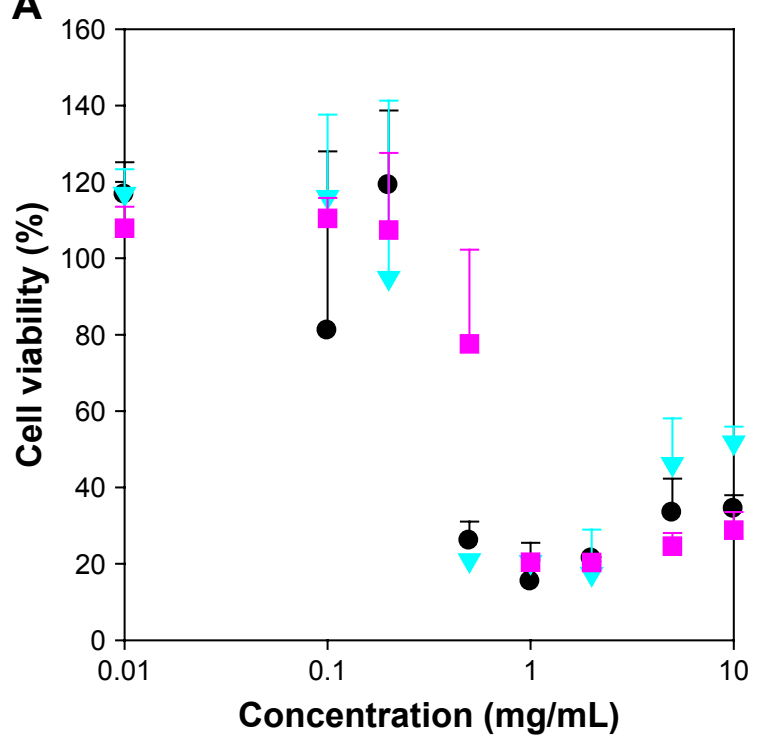

C

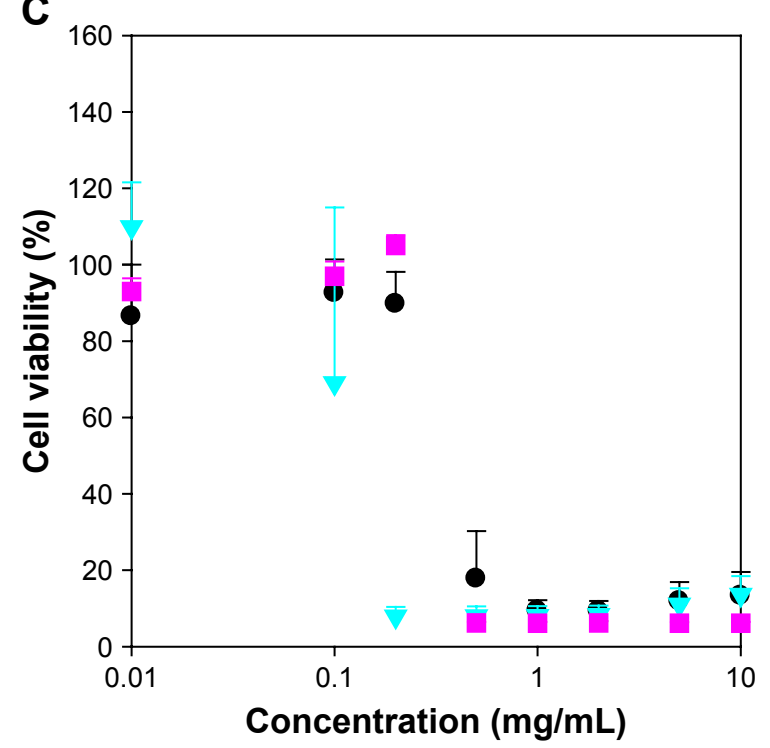

B

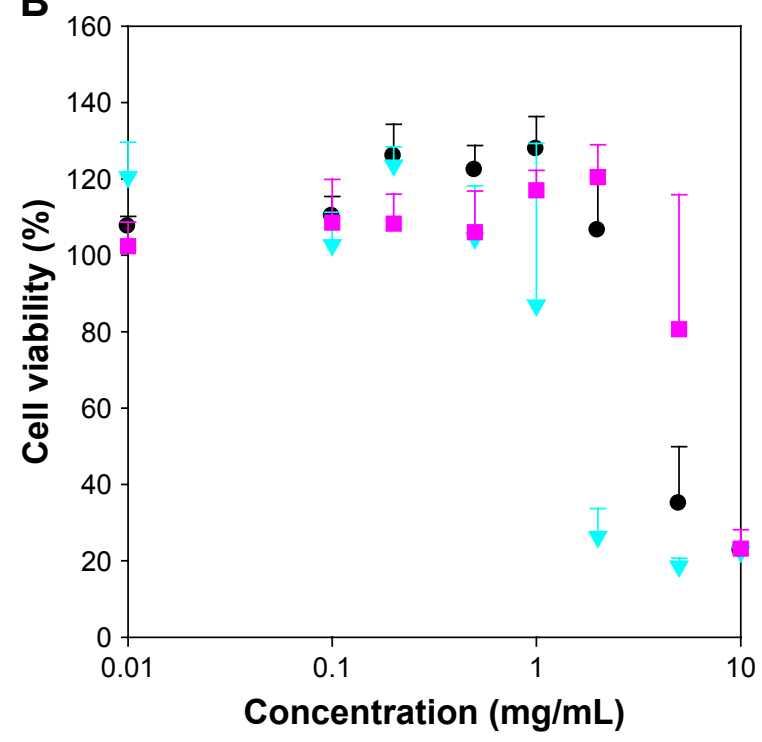

D

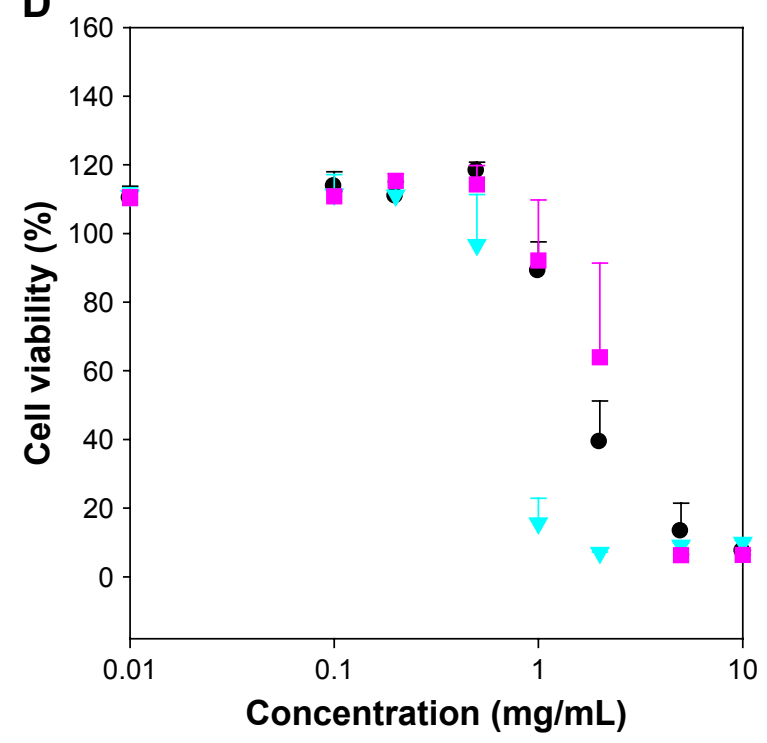

- Hybrid-ZnO $\quad \nabla$ Nano-ZnO $\quad$ Synthesized $\mathrm{ZnO}$

Figure 8 Cytotoxicity of synthesized $\mathrm{ZnO}$ nanoparticles in (A and $\mathbf{C})$ ARPE-19 and (B and D) $\mathrm{HaCaT}$ cells after (A and $\mathbf{B}) 48$ hours and (C and $\mathbf{D}) 72$ hours of incubation. Note: Conventional $\mathrm{ZnO}$ particles were used as controls.

Abbreviation: $\mathrm{ZnO}$, zinc oxide.

\section{Phototoxicity of $\mathrm{ZnO}$ nanoparticles}

$\mathrm{ZnO}$ nanoparticle phototoxicity was evaluated in $\mathrm{Balb} / \mathrm{c} 3 \mathrm{~T} 3$ cells by comparing neutral red uptake after dual UV irradiation of UV-A and UV-C with that after incubation in the dark. Cell viability and the average difference with/without UV irradiation were plotted at $0.001-1.0 \mathrm{mg} / \mathrm{mL}$ of synthesized $\mathrm{ZnO}$ nanoparticles (Figure 9A and B). The EC50 mean value and EC50 variance value of $\mathrm{ZnO}$ nanoparticles after UV irradiation were $0.098 \mathrm{mg} / \mathrm{mL}$, and $0.077 \mathrm{mg} / \mathrm{mL}$, respectively. $\mathrm{ZnO}$ nanoparticles at $0.1-1.0 \mathrm{mg} / \mathrm{mL}$ showed phototoxicity after dual UV irradiation of UV-A and UV-C (Figure 9C-F).
PIF and MPE values were C 14.331 and 0.138 , respectively, while PIF and MPE toxicity probability values were 0.900 and 0.745 , respectively. On the other hand, conventional hybrid- and nano-ZnO particles affected cell proliferation after dual UV irradiation (Figure S5). Hybrid-ZnO particles induced cell proliferation $(\sim 150 \%)$ at $0.1-1.0 \mathrm{mg} / \mathrm{mL}$ (Figure $\mathrm{S} 5 \mathrm{~A}$ and $\underline{\mathrm{C}}$ ) whereas nano-ZnO particles enhanced cell proliferation $(\sim 120 \%)$ at $0.001-0.1 \mathrm{mg} / \mathrm{mL}$ (Figure S5B and D). PIF and MPE values for hybrid-ZnO particles were $\mathrm{C} 1.000$ and -0.193 , resulting in toxicity probability values of 0.000 . In addition, PIF and MPE values 

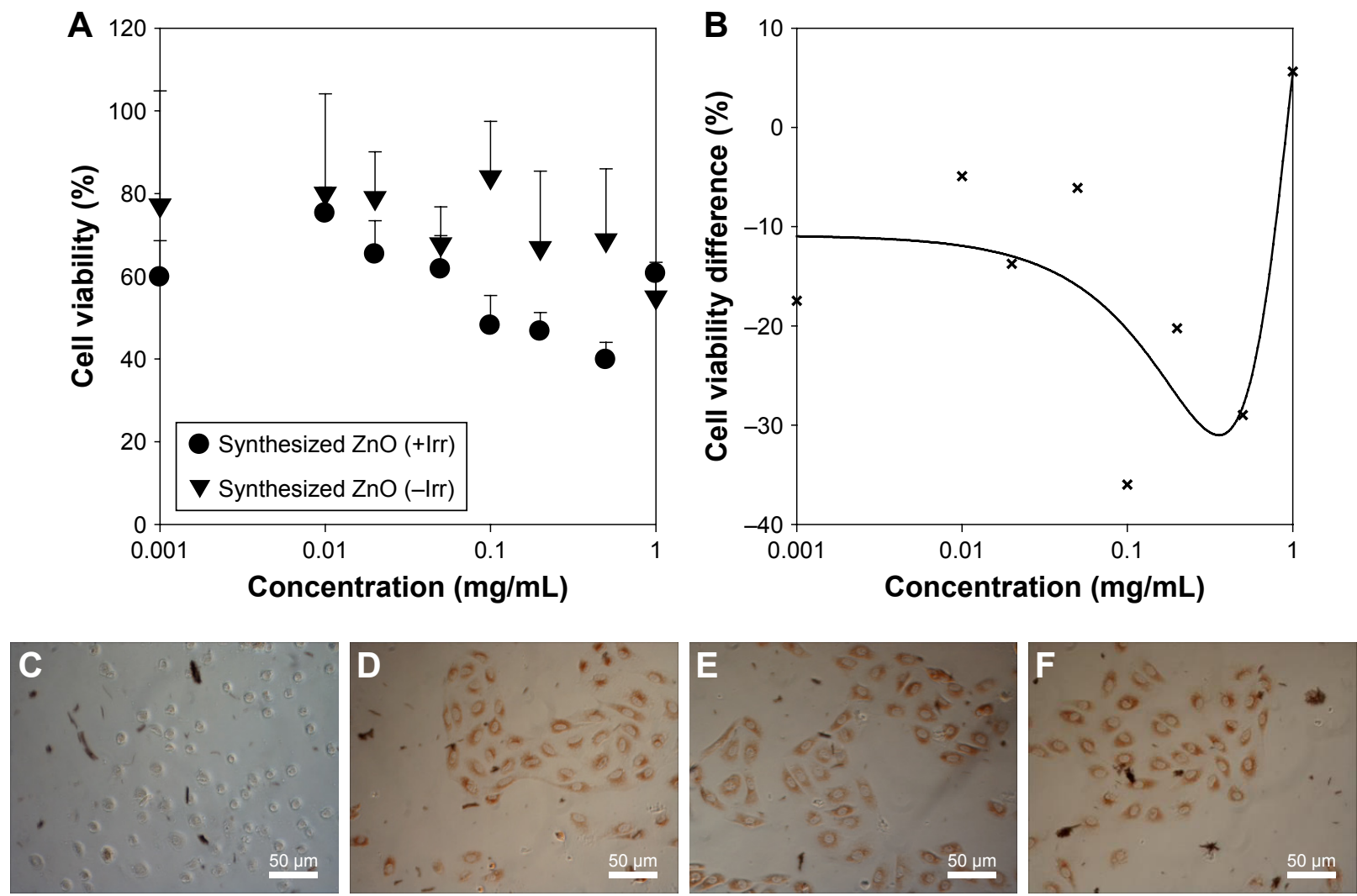

Figure 9 Phototoxicity of synthesized $\mathrm{ZnO}$ nanoparticles in Balb/c $3 \mathrm{~T} 3$ cells: (A) cell viability and (B) cell viability difference after UV irradiation-based $\mathrm{ZnO}$ nanoparticle treatment, and representative images of cells treated with (C) I.0, (D) 0.1 , (E) 0.05 , and (F) $0 \mathrm{mg} / \mathrm{mL} \mathrm{ZnO}$ nanoparticles.

Notes: +Irr: with UV irradiation, -Irr: without UV irradiation.

Abbreviations: UV, ultraviolet; $\mathrm{ZnO}$, zinc oxide.

of nano- $\mathrm{ZnO}$ particles were $\mathrm{C} 1.000$ and -0.288 with toxicity probability values of 0.000 . These results suggest that synthesized $\mathrm{ZnO}$ nanoparticles are "probably phototoxic" to "phototoxic" as strong photocatalysts under UV irradiation, although they showed low toxicity in skin and eye cells, as mentioned above. Conventional hybrid- and nano- $\mathrm{ZnO}$ particles affected cell proliferation levels.

\section{Discussion}

$\mathrm{ZnO}$ nanoparticles have been extensively studied due to their biocompatibility and similar band gap energy to $\mathrm{TiO}_{2}$ nanoparticles $(3.3 \mathrm{eV})$ and high electron mobility. ${ }^{1,2}$ They have been highlighted as natural alternatives to $\mathrm{TiO}_{2}$ nanoparticles in various research fields such as photocatalysis and energy storage. ${ }^{2,3,23}$ Among the bioapplications of $\mathrm{ZnO}$ nanoparticles, ${ }^{4-13}$ they have been reported to be photocatalytic antibiotics against bacteria and phages. ${ }^{5,6,8-13}$ For general antimicrobial therapy, $\mathrm{ZnO}$ nanoparticles also demonstrated therapeutic potential in human pathogens (minimum inhibitory concentration values: $30-80 \mu \mathrm{g} / \mathrm{mL}$ ), suggesting the possibility of their use as combination agents with other antibiotics such as cefotaxime and ceftriaxon. ${ }^{5,8-13}$ In the present study, the enhanced antibacterial activities of dual UV-irradiated $\mathrm{ZnO}$ nanoparticles and multilevel porous networks on $\mathrm{Si}$ wafers against $E$. coli have been reported. The physicochemical properties of these nanoparticles and networks were determined using XPS, FE-SEM, FE-TEM, and AFM. $\mathrm{ZnO}$ nanoparticle aggregates and arrayed networks had advantages that could maximize antibacterial activity based on the channel structure. ${ }^{14-21}$ Specifically, the arrayed networks are essential to minimize unpredicted particle exposure in the environment and to ensure human health. ${ }^{19,21}$ Antibacterial activity tests were also performed against $E$. coli. To determine the mechanisms of their antibacterial activity, GO analysis was performed for an $E$. coli database. Low-level cytotoxicity and phototoxicity for synthesized $\mathrm{ZnO}$ nanoparticles were also confirmed. Conventional $\mathrm{ZnO}$ particles of hybrid- $\mathrm{ZnO}$ and nano- $\mathrm{ZnO}$ were used as controls.

The physicochemical characteristics of synthesized $\mathrm{ZnO}$ nanoparticles were estimated for risk assessment. ${ }^{16,21}$ Characterization can provide information on morphology, surface, 
UV absorption, nanostructure, and $\mathrm{O}: \mathrm{Zn}$ ratio related to membrane sorption, ROS generation, and $\mathrm{Zn}$ ion release for antimicrobial activity and toxicity. ${ }^{5,17,22,23} \mathrm{ZnO}$ nanoparticles had sphere shapes with uneven surfaces $(<100 \mathrm{~nm}$ in diameter) (Figure 1). With regard to morphology and surface, synthesized $\mathrm{ZnO}$ nanoparticles were entirely different from conventional $\mathrm{ZnO}$ particles (Figure S1), suggesting synthesis method dependence. ${ }^{5,6,17}$ The atomic composition of $\mathrm{ZnO}$ nanoparticles was also related to material synthesis designs and techniques (Table 1). Binding energy levels of synthesized $\mathrm{ZnO}$ nanoparticles in XPS spectra were detected at the same peak positions as conventional $\mathrm{ZnO}$ particles (Figure S2). These are comparable to the previously reported results for $\mathrm{ZnO}$ nanoparticles. ${ }^{24} \mathrm{O}: \mathrm{Zn}$ ratios and UV absorption levels generally affect the ROS generation potential, which influence antimicrobial activity as well as toxicity. $5,17,21-24$

For macro-mesoporous channels, a synthesized $\mathrm{ZnO}$ nanoparticle suspension in hexane naturally formed layered nanostructures on Si wafers after solvent evaporation (Figure 2). EDS technique was used to investigate the characteristics of these engineered three-dimensional structures. ${ }^{25}$ An additively manufactured $\mathrm{ZnO}$ nanoparticle network by self-assembly was developed in a concentration-dependent manner. A multilevel porous $\mathrm{ZnO}$ nanoparticle network formed three-dimensional structures at higher concentrations than seen on the $0.5 \mathrm{mg} / \mathrm{Si}$ wafer. Hemisphere- to sphere-shaped $\mathrm{ZnO}$ nanoparticle aggregates with mesopores were formed on Si wafers in a low concentration suspension (0.05 mg/Si wafer; Figure 3). Conventional $\mathrm{ZnO}$ particles did not produce highly ordered networks of layered structures on Si wafers even at $0.5 \mathrm{mg} / \mathrm{Si}$ wafer (Figure S3).

Under dual UV irradiation (Figure 4), we applied synthesized $\mathrm{ZnO}$ nanoparticles (Figure 5) and arrayed $\mathrm{ZnO}$ nanoparticles on Si wafers (Figure 6) in antibacterial activity testing against $E$. coli in water. Synthesized $\mathrm{ZnO}$ nanoparticles had an enhanced activity at $0.05 \mathrm{mg} / \mathrm{mL}$ for 5 minutes under dual UV irradiation for 30 seconds compared with conventional $\mathrm{ZnO}$ particles. These results suggest that particle-particle and particle-aggregate interactions can enhance the antibacterial activity due to aggregate formation of synthesized $\mathrm{ZnO}$ nanoparticles in water compared with the antibacterial activity of hybrid-ZnO particles. Synthesized $\mathrm{ZnO}$ nanoparticles also had excellent antibacterial potential under dual UV irradiation in water samples from various facilities. These results are unique compared to those reported by Jin et al using $\mathrm{ZnO}$ nanoparticles at $1.0 \mathrm{mg} / \mathrm{mL}$ under uncoated dual UV irradiation for 30 seconds. ${ }^{6}$ Arrayed $\mathrm{ZnO}$ nanoparticles on $\mathrm{Si}$ wafers $(0.05 \mathrm{mg} / \mathrm{Si}$ wafer) showed superior antibacterial activity against $E$. coli $(>3 \log$ $\mathrm{CFU} / \mathrm{mL}$ ), even at shortened time of dual UV irradiation from 30 seconds to 10 seconds. $\mathrm{Zn}$ ion release was not detected from arrayed $\mathrm{ZnO}$ nanoparticles at $0.05 \mathrm{mg} / \mathrm{Si}$ wafer (Table S1). However, in the highest concentrations of hybrid- and nano-ZnO particles loaded on Si wafers (1.0 mg/Si wafer), aggregates were easily detached from $\mathrm{Si}$ wafers in water. Based on these results, arrayed $\mathrm{ZnO}$ nanoparticles on $\mathrm{Si}$ wafers showed a superior antibacterial activity compared with free $\mathrm{ZnO}$ nanoparticles despite previous studies indicating that the antimicrobial activity of $\mathrm{TiO}_{2}$ nanoparticles was reduced after immobilization. ${ }^{16,17,20}$

The antibacterial activity of $\mathrm{ZnO}$ nanoparticles and arrayed networks on solid plates was described using photocatalysis under dual UV irradiation (Figure 7). The representative action mechanisms of $\mathrm{ZnO}$ nanoparticles have been explained by 1) sorption into membranes and consequent membrane disruption and 2) ROS generation. 5,6,22,26 $\mathrm{ZnO}$ nanoparticles were highly sorptive on $E$. coli membranes based on hydrophobic and electrostatic interactions. After sorption, they endocytosed or broke down the membrane network and accumulated in E. coli. ${ }^{5,6} \mathrm{ZnO}$ nanoparticles and their aggregates can produce ROS including singlet oxygen $\left({ }^{1} \mathrm{O}_{2}\right)$, hydroxyl radicals $\left({ }^{\bullet} \mathrm{OH}\right)$, hydrogen peroxide $\left(\mathrm{H}_{2} \mathrm{O}_{2}\right)$, and superoxide $\left(\mathrm{O}_{2}^{-\bullet}\right)$ under $\mathrm{UV}$ irradiation. ${ }^{24}$ They induce oxidative stress of mitochondria and endoplasmic reticulum dysfunction in $E$. coli resulting in irreversible membrane damage, DNA mutation, and death in E. coli. Zn ion was not released from nanoparticles or nanoparticle networks, suggesting that nanoparticle antibacterial potential was not mediated by $\mathrm{Zn}$ ions.

Photocatalytic activity can also be improved by the multiple scattering induced by arrayed $\mathrm{ZnO}$ nanoparticles in threedimensional structure networks. ${ }^{27-29}$ Macro-mesoporous channel-based structure formation and multiple scattering in the nanoparticle networks were affected by physicochemical characteristics such as particle size and specific surface area. The zeta potential of $\mathrm{ZnO}$ nanoparticles was also related to aggregation formation in self-assembled nanostructureinduced photocatalysis enhancement. In general, $\mathrm{ZnO}$ nanoparticles showed positive zeta potential values at neutral to slightly basic $\mathrm{pH} .{ }^{30}$ The bimodal channels from interparticle interactions enhanced mass transfer in the networks. Compared to synthesized $\mathrm{ZnO}$ nanoparticles and conventional $\mathrm{ZnO}$ particles (hybrid- and nano-ZnOs), arrayed $\mathrm{ZnO}$ nanoparticles on Si wafers showed enhanced antibacterial activity without bacterial regrowth after treatment.

Using GO terms in a biology model, the interactions between $\mathrm{ZnO}$ nanoparticles and internal proteins in $E$. coli 
were investigated. GO terms with members are listed in Table S2. Using immobilized $\mathrm{ZnO}$ particles on $\mathrm{Si}$ wafers, the photocatalyst function of $\mathrm{ZnO}$ nanoparticles was focused on antibacterial potential more than $\mathrm{Zn}$ ion release and sorption to biomembrane in E. coli. GO terms with related proteins can explain the mechanism of action of the internal response of $E$. coli to oxidative stress; related protein expression can be modified for enhanced therapeutic effects. ${ }^{22-26}$ Proteins involved in oxidative stress on E. coli, specifically DNA-binding transcriptional dual regulator OxyR (oxyR) and protein/nucleic acid deglycase 3 (yajL), were searched in EcoCyc. ${ }^{22}$ OxyR and YajL act as "a bifunctional regulatory protein sensor for oxidative stress" and "a chaperone, protecting proteins in response to oxidative stress", respectively. In other words, OxyR in E. coli activates a hydrogen peroxide-inducible gene regulon as a hydrogen peroxide sensor for induction of a defense signal. ${ }^{29,31}$ YajL also has a repair catalysis function to deglycate Maillard adducts between protein amino groups/nucleotides and glyoxal reactive carbonyl groups. ${ }^{32,33}$ They protect against environmental oxidative stress in E. coli.

Nanoparticle toxicity is an important issue in nanoparticle development for various applications. In this study, techniques of damage-free repeated cell rinsing and reference subtraction were used to remove all artifacts. Synthesized $\mathrm{ZnO}$ nanoparticles showed lower cytotoxicity in $\mathrm{HaCaT}$ (Figure S4) and ARPE-19 cells than conventional hybrid- and nano- $\mathrm{ZnO}$ particles (Figure 8 ). The slight cell proliferation potential of $\mathrm{ZnO}$ nanoparticles at $0.5-200 \mu \mathrm{g} / \mathrm{mL}$ has already been reported in $\mathrm{HaCaT}$ after 24-hour incubation. ${ }^{34}$ IC50 values of $\mathrm{ZnO}$ nanoparticles (synthesized $\mathrm{ZnO}, 6.632 \mathrm{mg} / \mathrm{mL}$; hybrid-ZnO, $4.476 \mathrm{mg} / \mathrm{mL}$; nano- $\mathrm{ZnO}, 1.736 \mathrm{mg} / \mathrm{mL}$ ) were much higher than previously reported $\mathrm{ZnO}$ nanoparticle results. Vinardell et al reported the IC50 values of $\mathrm{ZnO}$ $(50 \mathrm{~nm})$ and $\mathrm{ZnO}(100 \mathrm{~nm})$ nanoparticles to be around 50 and $40 \mu \mathrm{g} / \mathrm{mL}$, respectively, in HaCaT cells after a 48-hour incubation period. ${ }^{35}$ Genç et al also reported that nanoscale to microscale $\mathrm{ZnO}$ particles showed lower toxicity in $\mathrm{HaCaT}$ cells than $\mathrm{ZnO}$ nanoparticles $(<100 \mathrm{~nm}$ in diameter) with/ without UV-A and UV-B. ${ }^{36}$ Compared to $\mathrm{TiO}_{2}$ nanoparticle toxicity, $\mathrm{TiO}_{2}$ nanoparticles had an autophagic effect on $\mathrm{HaCaT}$ cells in a dose-dependent manner even at noncytotoxic levels. ${ }^{37}$ Synthesized $\mathrm{ZnO}$ nanoparticles were phototoxic under dual UV irradiation (UV-A and UV-C; Figure 9) compared with conventional $\mathrm{ZnO}$ particles on $\mathrm{Balb} / \mathrm{c} 3 \mathrm{~T} 3$ cells (Figure S5)

Overall, $\mathrm{ZnO}$ nanoparticles and their immobilized network on Si wafers had excellent disinfection potential as photocatalysts under dual UV irradiation. Sophisticated three-dimensional $\mathrm{ZnO}$ structures formed with multilevel porosity via self-assembly. They showed superior antibacterial activity against $E$. coli at $>3 \log \mathrm{CFU} / \mathrm{mL}$ without environmental or health exposure risks. Although synthesized $\mathrm{ZnO}$ nanoparticles were phototoxic, they were less toxic in skin and eye cells than conventional $\mathrm{ZnO}$ particles. These results suggest that $\mathrm{ZnO}$ nanoparticles and self-assembled $\mathrm{ZnO}$ nanoparticle networks on solid plates can be implemented in the dual UV irradiation systems as effective and safe photocatalytic antibiotics. Their application can also be extended to highly pathogenic microorganisms for enhanced disinfection, suggesting their promising potential in near-future disinfection systems for clinical and industrial uses.

\section{Conclusion}

$\mathrm{ZnO}$ nanoparticles were synthesized and immobilized onto the solid plates ( $\mathrm{Si}$ wafers). Three-dimensional $\mathrm{ZnO}$ nanoparticle networks formed hierarchically porous nanostructures on Si wafers via self-assembly after solvent evaporation. Synthesized $\mathrm{ZnO}$ nanoparticles and arrayed $\mathrm{ZnO}$ nanoparticle networks on solid plates had excellent antibacterial activity against $E$. coli under dual UV irradiation at $>3 \log C F U / m L$. Immobilized forms of arrayed $\mathrm{ZnO}$ nanoparticles showed superior antibacterial activity compared with synthesized $\mathrm{ZnO}$ nanoparticles. Membrane sorption and ROS generation without $\mathrm{Zn}$ ion release were included in the main antibacterial mechanisms of action. In immobilized $\mathrm{ZnO}$ nanoparticle networks on solid plates, multiple scattering and bimodal channel structures could enhance the antibacterial activity against $E$. coli despite the reduction of membrane sorption potential. With regard to cellular response, OxyR and YajL proteins were searched in GO term members related to oxidative stress in E. coli. Synthesized $\mathrm{ZnO}$ nanoparticles had lower toxicity in skin and eye cells than conventional $\mathrm{ZnO}$ particles; however, they were phototoxic. These results suggest that dual UV-irradiated $\mathrm{ZnO}$ nanoparticles and self-assembled nanoparticle networks on solid plates have antibacterial effects against $E$. coli. In addition, they show considerable promise as photocatalytic nanoantibiotics for use in near future disinfection systems with industrial and clinical applications.

\section{Acknowledgments}

This work was partially supported by the Korea Ministry of Environment (MOE) as part of "The advancement of scientific research and technological development in environmental science program (2016000140006)". Prof 
Jong-Wha Jung and Minjun Kim, PhD candidate, kindly provided $\mathrm{ZnO}$ nanoparticles.

\section{Disclosure}

The authors report no conflicts of interest in this work.

\section{References}

1. Solanki PR, Kaushik A, Agrawal VV, Malhotra BD. Nanostructured metal oxide-based biosensors. NPG Asia Mater. 2011;3(1):17-24.

2. Yu X, Marks TJ, Facchetti A. Metal oxides for optoelectronic applications. Nat Mater. 2016;15(4):383-396.

3. Abd-El-Aziz AS, Agatemor C, Etkin N. Antimicrobial resistance challenged with metal-based antimicrobial macromolecules. Biomaterials. 2017;118:27-50.

4. Allahverdiyev AM, Abamor ES, Bagirova M, Rafailovich M. Antimicrobial effects of $\mathrm{TiO}_{(2)}$ and $\mathrm{Ag}_{(2)} \mathrm{O}$ nanoparticles against drug-resistant bacteria and Leishmania parasites. Future Microbiol. 2011;6(8): 933-940.

5. Amna S, Shahrom M, Azman S. Review on zinc oxide nanoparticles: antibacterial activity and toxicity mechanism. Nano-Micro Lett. 2015; 7(3):219-242.

6. Jin SE, Hwang W, Lee HJ, Jin HE. Dual UV irradiation-based metal oxide nanoparticles for enhanced antimicrobial activity in Escherichia coli and M13 bacteriophage. Int J Nanomedicine. 2017;12:8057-8070.

7. Jin SE, Ahn HS, Kim JH, et al. Boiling method-based zinc oxide nanorods for enhancement of adipose-derived stem cell proliferation. Tissue Eng Part C Methods. 2016;22(9):847-855.

8. Mirhosseini M, Firouzabadi FB. Antibacterial activity of zinc oxide nanoparticle suspensions on food-borne pathogens. Int J Dairy Technol. 2013;66(2):291-295.

9. Liu J, Rojas-Andrade MD, Chata G, et al. Photo-enhanced antibacterial activity of $\mathrm{ZnO} /$ graphene quantum dot nanocomposites. Nanoscale. 2018;10(1):158-166.

10. Raja A, Ashokkumar S, Pavithra Marthandam R, et al. Eco-friendly preparation of zinc oxide nanoparticles using Tabernaemontana divaricata and its photocatalytic and antimicrobial activity. J Photochem Photobiol B. 2018;181:53-58.

11. Bhande RM, Khobragade CN, Mane RS, Bhande S. Enhanced synergism of antibiotics with zinc oxide nanoparticles against extended spectrum $\beta$-lactamase producers implicated in urinary tract infections. J Nanopart Res. 2013;15(1):1413.

12. Aditya A, Chattopadhyay S, Jha D, Gautam HK, Maiti S, Ganguli M. Zinc oxide nanoparticles dispersed in ionic liquids show high antimicrobial efficacy to skin-specific bacteria. ACS Appl Mater Interfaces. 2018;10(18):15401-15411.

13. Kadiyala U, Turali-Emre ES, Bahng JH, Kotov NA, VanEpps JS. Unexpected insights into antibacterial activity of zinc oxide nanoparticles against methicillin resistant Staphylococcus aureus (MRSA). Nanoscale. 2018;10(10):4927-4939.

14. Alrousan DM, Dunlop PS, McMurray TA, Byrne JA. Photocatalytic inactivation of $E$. coli in surface water using immobilised nanoparticle $\mathrm{TiO}_{2}$ films. Water Res. 2009;43(1):47-54.

15. Ede S, Hafner L, Dunlop P, Byrne J, Will G. Photocatalytic disinfection of bacterial pollutants using suspended and immobilized $\mathrm{TiO}_{2}$ powders. Photochem Photobiol. 2012;88(3):728-735.

16. Zheng X, Shen G, Wang C, et al. Bio-inspired Murray materials for mass transfer and activity. Nat Commun. 2017;8:14921.

17. Baranwal A, Srivastava A, Kumar P, Bajpai VK, Maurya PK, Chandra P. Prospects of nanostructure materials and their composites as antimicrobial agents. Front Microbiol. 2018;9:422.
18. Avci C, Imaz I, Carné-Sánchez A, et al. Self-assembly of polyhedral metal-organic framework particles into three-dimensional ordered superstructures. Nat Chem. 2017;10(1):78-84.

19. Zhang J, Li Y, Zhang X, Yang B. Colloidal self-assembly meets nanofabrication: from two-dimensional colloidal crystals to nanostructure arrays. Adv Mater. 2010;22(38):4249-4269.

20. Schneider D, Mehlhorn D, Zeigermann P, Kärger J, Valiullin R. Transport properties of hierarchical micro-mesoporous materials. Chem Soc Rev. 2016;45(12):3439-3467.

21. Yu L, Zheng-yi F, Bao-lian S. Hierarchically structured porous materials for energy conversion and storage. Adv Funct Mater. 2012; 22(22):4634-4667.

22. Keseler IM, Mackie A, Santos-Zavaleta A, et al. The EcoCyc database: reflecting new knowledge about Escherichia coli K-12. Nucleic Acids Res. 2017;45(D1):D543-D550.

23. Boken J, Soni SK, Kumar D. Microfluidic synthesis of nanoparticles and their biosensing applications. Crit Rev Anal Chem. 2016;46(6):538-561.

24. Yuan G, Xiang J, Jin H, Wu L, Jin Y, Zhao Y. Anchoring ZnO nanoparticles in nitrogen-doped graphene sheets as a high-performance anode material for lithium-ion batteries. Materials (Basel). 2018;11(1):96.

25. Nagarajan S, Arumugam Kuppusamy K. Extracellular synthesis of zinc oxide nanoparticle using seaweeds of Gulf of Mannar, India. J Nanobiotechnology. 2013;11(1):39.

26. Dizaj SM, Lotfipour F, Barzegar-Jalali M, Zarrintan MH, Adibkia K. Antimicrobial activity of the metals and metal oxide nanoparticles. Mater Sci Eng C. 2014;44:278-284.

27. Yang XY, Chen LH, Li Y, Rooke JC, Sanchez C, Su BL. Hierarchically porous materials: synthesis strategies and structure design. Chem Soc Rev. 2017;46(2):481-558

28. Parlett CM, Wilson K, Lee AF. Hierarchical porous materials: catalytic applications. Chem Soc Rev. 2013;42(9):3876-3893.

29. Christman MF, Storz G, Ames BN. OxyR, a positive regulator of hydrogen peroxide-inducible genes in Escherichia coli and Salmonella typhimurium, is homologous to a family of bacterial regulatory proteins. Proc Natl Acad Sci U S A. 1989;86(10):3484-3488.

30. Marsalek R. Particle size and zeta potential of ZnO. APCBEE Procedia. 2014;9:13-17

31. Storz G, Tartaglia LA. OxyR: a regulator of antioxidant genes. J Nutr. 1992;122(3 Suppl):627-630.

32. Le HT, Gautier V, Kthiri F, et al. YajL, prokaryotic homolog of parkinsonism-associated protein DJ-1, functions as a covalent chaperone for thiol proteome. J Biol Chem. 2012;287(8):5861-5870.

33. Abdallah J, Mihoub M, Gautier V, Richarme G. The DJ-1 superfamily members $\mathrm{YhbO}$ and yajL from Escherichia coli repair proteins from glycation by methylglyoxal and glyoxal. Biochem Biophys Res Commun. 2016;470(2):282-286.

34. Gao F, Ma N, Zhou H, et al. Zinc oxide nanoparticles-induced epigenetic change and G2/M arrest are associated with apoptosis in human epidermal keratinocytes. Int J Nanomedicine. 2016;11:3859-3874.

35. Vinardell M, Llanas H, Marics L, Mitjans M. In vitro comparative skin irritation induced by nano and non-nano zinc oxide. Nanomaterials (Basel). 2017;7(3):56.

36. Genç H, Barutca B, Koparal AT, Özöğüt U, Şahin Y, Suvacı E. Biocompatibility of designed MicNo-ZnO particles: cytotoxicity, genotoxicity and phototoxicity in human skin keratinocyte cells. Toxicol In Vitro. 2018;47:238-248.

37. Lopes VR, Loitto V, Audinot J-N, Bayat N, Gutleb AC, Cristobal S. Dose-dependent autophagic effect of titanium dioxide nanoparticles in human $\mathrm{HaCaT}$ cells at non-cytotoxic levels. J Nanobiotechnology. 2016;14(1):22. 
International Journal of Nanomedicine

Dovepress

\section{Publish your work in this journal}

The International Journal of Nanomedicine is an international, peerreviewed journal focusing on the application of nanotechnology in diagnostics, therapeutics, and drug delivery systems throughout the biomedical field. This journal is indexed on PubMed Central, MedLine, CAS, SciSearch $®$, Current Contents $® /$ Clinical Medicine,
Journal Citation Reports/Science Edition, EMBase, Scopus and the Elsevier Bibliographic databases. The manuscript management system is completely online and includes a very quick and fair peer-review system, which is all easy to use. Visit http://www.dovepress.com/ testimonials.php to read real quotes from published authors.

Submit your manuscript here: http://www.dovepress.com/international-journal-of-nanomedicine-journal 